14

\title{
Физико-химические свойства и структура костного матрикса при смоделированном туберкулезном остите
}

\author{
(C) В.К. Крутько, ${ }^{1}$ В.В. Казбанов, ${ }^{2,3}$ О.Н. Мусская, ${ }^{1}$ А.А. Гайдаш, ${ }^{2,3}$ А.И. Кулак, ${ }^{1}$ Н.М. Чекан, \\ М.C. Сердобинцев, ${ }^{2}$ К.В. Скроцкая ${ }^{5}$ \\ ${ }^{1}$ Институт общей и неорганической химии НАН Беларуси, \\ 220079 Минск, Беларусь \\ ${ }^{2}$ Санкт-Петербургский научно-исследовательский институт фтизиопульмонологии, \\ 191036 Санкт-Петербург, Россия \\ ${ }^{3}$ Республиканский научно-практический центр детской хирургии, \\ 220013 Минск, Беларусь \\ ${ }^{4}$ Физико-технический институт НАН Беларуси, \\ 220141 Минск, Беларусь \\ ${ }^{5}$ Научно-исследовательский институт фризико-химических проблем, \\ 220030 Минск, Беларусь \\ e-mail: tsuber@igic.bas-net.by
}

(Поступило в Редакцию 26 марта 2018 г.)

Исследованы физико-химические свойства и структура костного матрикса при смоделированном туберкулезном остите без лечения и после полного курса специфической антибактериальной терапии. Методами рентгенофазового анализа, ИК-спектроскопии, термического анализа и сканирующей электронной микроскопии установлено, что при туберкулезном остите происходит мелкодисперсный распад костного матрикса вследствие увеличения количества нестехиометрического гидроксиапатита, образования аморфизированных фосфатов кальция и уменьшения органической фазы, что сопровождается охрупчением костного матрикса. Избыточный рост кристаллов карбонат-гидроксиапатита смешанного АБ-типа замещения приводит к чрезмерному остеогенезу, сопровождающемуся хаотичным разрастанием костных трабекул. Наличие в кристаллической решетке гидроксиапатита областей „известкования“ повышает „вяжущие“ свойства костного матрикса, в котором происходит иммобилизация микобактерий и их вынос в составе детрита.

DOI: $10.21883 / 0000000000$

\section{Введение}

Туберкулезные поражения костей и суставов часто встречаются в клинических формах внелегочного туберкулеза, который сложно диагностировать и лечить [1]. Одним из ранних проявлений развивающегося туберкулезного остита является остеопоротическая трансформация [2], которая осложняется очаговым распадом и секвестрированием костного матрикса. Механизмы остеопоротической трансформации костного матрикса и сдвигов процессов ремоделирования костной ткани при туберкулезных оститах во многом остаются неясными. В особенности это касается малых форм, например, вакцинальные оститы, которые хорошо поддаются специфическому антибактериальному лечению и склонны к „самозалечиванию“. В таких условиях остеопороз является триггером [2], создающим структурные и физико-химические предпосылки, реализующие остеолиз и остеогенез.

До настоящего времени физико-химические свойства минеральной фазы, регенерирующей кости, остаются мало изученными при том, что ее основу составляют фосфаты кальция, составляющие около $50 \%$ от объема костного матрикса, что в значительной мере определяет механические и структурообразующие свойства кости в целом. Еще менее изучены физико-химические преобразования костного матрикса при туберкулезном остите, заболеваемость которым в особенности малыми формами растет. Не ясны и ультраструктурные изменения внеклеточного матрикса в ходе физиологического ремоделирования костной ткани. Целью настоящей работы являлось исследование физико-химических свойств и ультраструктурных изменений костного матрикса в норме и в условиях смоделированного туберкулезного остита без лечения и после полного курса специфической антибактериальной терапии.

\section{Объекты и методы исследования}

Эксперименты выполнены на половозрелых самцах кроликов породы Шиншилла на базе экспериментальной лаборатории Научно-исследовательского института фтизиопульмонологии (Санкт-Петербург). Протоколы экспериментов согласованы с этическим комитетом и соответствуют Правилам работы с лабораторными животными, утвержденных Министерством здравоохранения Российской Федерации. Контрольная 1-я группа составлена из здоровых кроликов. У кроликов 2-й и 3-й групп был смоделирован туберкулезный остит путем введения культуры туберкулезных микобактерий в метаэпифизы бедренных костей. После формирования первичного 
очага (его наличие верифицировали рентгенологически) удаляли некротические массы и наблюдали в течение 1-2 месяцев. Во 2-й группе животных специфического лечения не проводили, а в 3-й группе кроликов была проведена стандартная противотуберкулезная терапия. Каждая группа составлена из трех особей, содержавшихся на стандартном рационе. Из эксперимента животных выводили с помощью летальных доз золетила. Образцы костной ткани вырезали из первичного очага и фиксировали в 2.5\% глутаровом альдегиде, приготовленном на фосфатном буфере. Затем охлаждали в жидком азоте, в среде которого делали серийные сколы.

В качестве эталона сравнения использовали порошок синтетического [3-5] аморфизированного гидроксиапатита (ГА) $\mathrm{Ca}_{10}\left(\mathrm{PO}_{4}\right)_{6}(\mathrm{OH})_{2}$, высушенный при $60^{\circ} \mathrm{C}$ до постоянной массы, максимально приближенный по структуре и свойствам к минеральной составляющей костной ткани.

Фазовый состав порошкового костного матрикса, высушенного до постоянной массы на воздухе, определяли методом рентгенофазового анализа (РФА) на дифрактометре ADVANCE D8 (Bruker, Германия) при $\mathrm{Cu}_{K \alpha}=1.5405 \AA$. ИК-спектроскопию проводили на спектрометре Tenzor-27 (Bruker, Германия) в диапазоне 400-4000 $\mathrm{cm}^{-1}$ (1 mg костного порошка на $800 \mathrm{mg} \mathrm{KBr}$ ). Дифференциально-термический анализ (ДТА) проводили на совмещенном термическом анализаторе NETZSCHSTA 409 PCLUXX (Германия) при скорости нагрева $10.0^{\circ} \mathrm{C} / \mathrm{min}$ на воздухе (масса навески $\sim 40 \mathrm{mg})$. Сканирующую электронную микроскопию (СЭМ) костных срезов выполняли на микроскопе LEO 1420, совмещенном с приставкой элементного анализа Rontec (Германия), предварительно на поверхность образцов напыляли золото.

\section{Результаты и их обсуждение}

В эксперименте по данным РФА установлено, что минеральная составляющая здоровой костной ткани представлена в большей степени аморфизированным ГА по сравнению с синтетическим ГА (рис. 1, дифрактограммы 1,4). Причем минеральная компонента костной ткани представлена 58\% нестехиометрического ГА и $42 \%$ карбонат-ГА, что согласуется с литературными данными [6,7]. При туберкулезном остите происходит значительное уменьшение интенсивности рефлексов, связанных с органической фазой, на фоне существенного увеличения количества нестехиометрического ГА и уменьшения размера кристаллитов как нестехиометрического ГА, так и карбонат-ГА (рис. 1, дифрактограмма 2). На дифрактограмме образца с туберкулезным оститом наблюдается значительное уширение рентгеноаморфного гало, что свидетельствует о максимальной аморфизации ГА. Можно предположить, что в данном случае на степень аморфизации влияют протекающие патологические процессы [8] и, в частно-

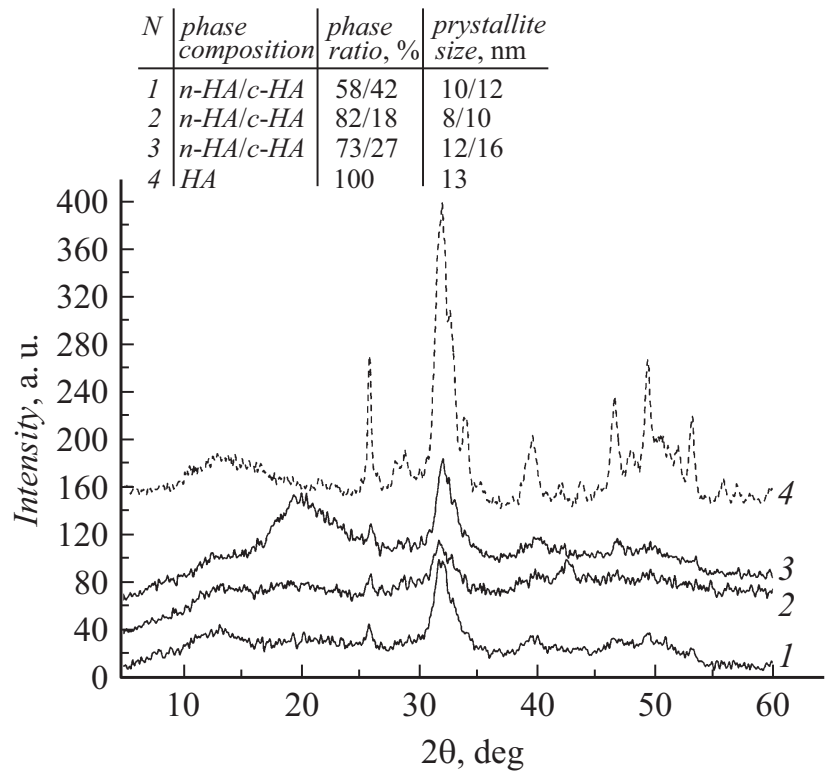

Рис. 1. Дифрактограммы костного матрикса после 1 месяца: 1 - норма, 2 - при туберкулезном остите, 3 - при туберкулезном остите после лечения, 4 - синтетический ГА, высушен при $60^{\circ} \mathrm{C} ; n-H A / c-H A-$ нестехиометрический ГА/карбонат-ГА.

сти, алкалоз, характерный для туберкулезной интоксикации. В условиях лечения происходит восстановление коллагенового каркаса костного матрикса, на волокнах которого осуществляется эпитаксиальный рост кристаллитов ГА [2], что подтверждается данными РФА в виде рентгеноаморфного гало при малых углах $2 \theta 16-25^{\circ}$ (рис. 1, дифрактограмма 3) и некоторым повышением степени кристалличности и размера кристаллитов ГА. По-видимому, в регенерирующем костном матриксе формируется слабокислая среда, характерная для регенерации, что подтверждается повышением количества „кислого“ карбонат-ГА.

Результаты ИК-спектроскопии согласуются с данными РФА костных порошков, и уширение полос на ИКспектрах свидетельствует о снижении кристалличности фосфатов кальция. На ИК-спектрах костных порошков всех групп животных (рис. 2, кривые 1-3) уширены валентные и деформационные колебания тетраэдров $\mathrm{PO}_{4}^{3-}$ при 1090, 1030, 970, 635, 613 и $560 \mathrm{~cm}^{-1}$, что указывает на искажения кристаллической решетки ГА [9]. Присутствие адсорбированной воды в образцах подтверждается широкой полосой поглощения при $3550-3200 \mathrm{~cm}^{-1}$ валентных колебаний воды и полосой при $1650 \mathrm{~cm}^{-1}$ деформационных колебаний воды. Структурные ОНгруппы, координированные катионом $\mathrm{Ca}^{2+}$ и не связанные водородными связями у синтетического ГА, представлены полосой при $3574 \mathrm{~cm}^{-1}$ (рис. 2, кривая 4), а у костных порошков происходит сдвиг данной полосы до $3744 \mathrm{~cm}^{-1}$ (рис. 2, кривые 1-3). Наличие органической фазы подтверждается присутствием полос при 




Рис. 2. ИК-спектры костного матрикса после 1 месяца: 1 норма, 2 - при туберкулезном остите, 3 - при туберкулезном остите после лечения, 4 - синтетический ГА, высушен при $60^{\circ} \mathrm{C}$.

3551, 3468, 3414, $3204 \mathrm{~cm}^{-1}$ валентных колебаний связей $\mathrm{N}-\mathrm{H}$ и $-\mathrm{NH}_{2}$, которые перекрываются валентными колебаниям связи О-Н; в области $2927-2855 \mathrm{~cm}^{-1}-$ связей $\mathrm{C}-\mathrm{H},-\mathrm{CH}_{2}-$; при $1745 \mathrm{~cm}^{-1}-$ связи $\mathrm{C}=\mathrm{O}[10]$. Наличие значительного количества органической фазы, характерной для 3-й группы животных, после лечения подтверждается резким возрастанием интенсивностей полос $\mathrm{C}-\mathrm{H},-\mathrm{CH}_{2}-$ и $\mathrm{C}=\mathrm{O}$ связей (рис. 2, кривая 3) по отношению к норме и при туберкулезном остите.

Полосы поглощения связи $\mathrm{C}-\mathrm{O}$ карбонат-ионов при $1520,1462,1412 \mathrm{~cm}^{-1}$ свидетельствуют о накоплении ионов $\mathrm{CO}_{3}^{2-}$ в анионной подрешетке ГА $[11,12]$ и подтверждаются данными РФА о присутствии фазы карбонат-ГА. Из ИК-спектров можно предположить, что наличие полос поглощения при 1460, 1412 и $1520 \mathrm{~cm}^{-1}$ свидетельствует о замещении на карбонат-ионы, которое может происходить как по А-типу (вместо $\mathrm{OH}^{-}$), так и по В-типу (вместо $\mathrm{PO}_{4}^{3-}$ ) $[13,14]$. Причем доминирование механизма анионного замещения по Втипу характерно для образцов 1-й и 3-й групп, а у 2-й группы при туберкулезном остите преобладает Атип замещения вследствие увеличения интенсивности полосы поглощения карбонат-ионов при $1520 \mathrm{~cm}^{-1}$ и значительного сдвига полосы ОН-группы до $3744 \mathrm{~cm}^{-1}$. Отметим, что $\mathrm{CO}_{3}^{2-}$ замещения оказывают деформирующее воздействие на структуру ГА, из-за структурного несоответствия плоских треугольной формы анионов $\mathrm{CO}_{3}^{2-}$, замещающих фосфат-ионы $\mathrm{PO}_{4}^{3-}$, имеющие форму тетраэдров [9]. Поэтому в замещенных участках структуры ГА могут возникать центры напряжения, в решетке тетраэдрического фосфат-иона появляются искажения и кристалл становится менее устойчивым. Вследствие карбонатных замещений уменьшается концентрация гидроксильных групп, колебательные движения атомов в связи $\mathrm{P}-\mathrm{O}$ разупорядочиваются, что дез- организует параллельную укладку кристаллитов и, как следствие, замедляется их эпитаксиальный рост. В итоге можно ожидать повышения химической активности и резорбируемости кристаллитов ГА.

Кроме того, в костном матриксе при туберкулезном остите увеличивается интенсивность широкой полосы в интервале при $3414-3550 \mathrm{~cm}^{-1}$ (рис. 2, кривая 2), что может свидетельствовать о появлении в структуре ГА колебаний связей „известкового“ типа $\mathrm{Ca}-\mathrm{OH}$. Механизмы данных структурных искажений не ясны, но, очевидно, что туберкулезные микобактерии имеют сродство к потенциально „известковым“ центрам ГА, формирование которых сопровождается экзотермической реакцией и придает кристаллитам и костному матриксу в целом „вяжущие“ свойства.

Методом термического анализа установлено, что потери массы образцов наблюдаются в четырех температурных интервалах (рис. 3). В первом интервале при $70-200^{\circ} \mathrm{C}$ происходит потеря адсорбированной воды, что в большей степени выражено для образца 1-й контрольной группы (рис. 3, кривые 1). Далее при $200-400^{\circ} \mathrm{C}$ удаляется структурная вода и неколлагеновые белки [14]. Причем в патологических условиях дегидратация происходит при меньших энергетических затратах вследствие изменения геометрических параметров ультратонких каналов коллагеновой матрицы, что свидетельствует об их остеопоротической трансформации (было показано ранее при остеопорозе [2]). В третьем интервале при $400-550^{\circ} \mathrm{C}$ разрушается коллаген, и эта стадия более выражена для образца 3-й группы после лечения (рис. 3, кривые 3), в котором содержится наибольшее количество новообразованной органической фазы. При $550-900^{\circ} \mathrm{C}$ удаляется углекислый газ из минеральной компоненты костного матрикса вследствие перехода карбонат-ГА в стехиометрический ГА [10,11]. Следует отметить, что у образца костного матрикса с туберкулезным оститом (рис. 3, кривые 2) третья стадия начинается раньше при $500^{\circ} \mathrm{C}$, что может быть связано с наличием значительного количества аморфизированных

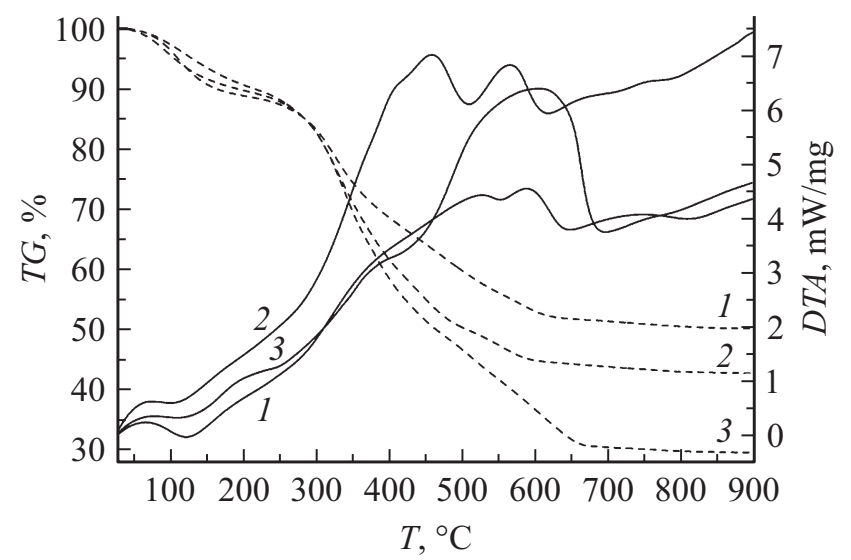

Рис. 3. ТГ и ДТА кривые костного матрикса после 1 месяца: 1 - норма, 2 - при туберкулезном остите, 3 - при туберкулезном остите после лечения. 



Рис. 4. СЭМ-изображения микобактерий, ориентированных вблизи поровых структур (a) и иммобилизованных в клетках Лангханса $(b)$.

фаз фосфатов кальция и наименьшего содержания органической фазы.

Наличие прогрессирующего туберкулезного остита верифицируется обнаружением в костном матриксе некротической ткани и прилежащих к первичному очагу костной ткани микобактерий туберкулеза типичной формы (рис. 4). Морфологически бактериальные частицы имеют вид полузакругленных цилиндров, некоторые из них образуют структуру в виде „полных колец“ (рис. 4,a). Причем в глубине матрикса на расстоянии до $5 \mathrm{~mm}$ от края первичного очага обнаруживаются типичные клетки Лангханса - макрофаги, поглотившие микобактерии (рис. 4,b), которые выпускают множественные цитоплазматические отростки, посредством которых фиксируются к свободным поверхностям костного матрикса. Возможно это связано с тем, что подобная фиксация макрофагов, заполненных микобактериями, наблюдается главным образом в просветах микроканальцев или других патологически свободных пространств (интерстициальные щели, расширенные межклеточные пространства в зонах остеопороза). Таким образом, формируются структурные предпосылки для достаточно глубокого, до 5-7 mm от края очага, проникновения макрофагальных носителей микобактерий.

Методом СЭМ-морфометрии установлено, что отношение объемов регенерирующей костной ткани к плотной фракции костного матрикса варьирует в близких пропорциях к отношению „кислого“ и нестехиометрического ГА. Такое совпадение не случайно и позволяет предположить, что „кислый“ карбонат-ГА сосредоточен преимущественно в очагах регенерации, а более „щелочной“6 нестехиометрический ГА накапливается в плотных участках костного матрикса. Об обогащении гидроксидными группами, „защелачивающими“ плотные участки, свидетельствует об увеличении размеров кристаллитов ГА до $13 \mathrm{~nm}$, а также увеличении соотношения $\mathrm{Ca} / \mathrm{P}$ до 3.06 (в зоне регенерации $\mathrm{Ca} / \mathrm{P}=2.71$ ), что свидетель- ствует об отложении примесных кальцийфосфатных фаз при туберкулезном остите.

По данным СЭМ (рис. 5, $a, b)$ в костном матриксе у животных 2-й группы с туберкулезным оститом выявляется резко выраженная остеопоротическая трансформация с очаговым разрежением и истончением костных трабекул. Остеопоротическая трансформация сопровождается мелкодисперсным распадом и массовым лизисом костного матрикса. К двум месяцам развития смоделированного туберкулезного остита (рис. $5, b)$ мелкодисперсный распад костного матрикса в краевых отделах кости, прилежащих к очагу, достигает своего максимума. Можно предположить, что остеопоротическая трансформация в зоне деструкции создает предпосылки для накопления фильтрующихся форм микобактерий туберкулеза, а в целом способствует появлению бацилл с лекарственной устойчивостью.

Следовательно, при туберкулезном остите плотный матрикс выглядит как „растрескивающийся“ на микрометровом уровне бесструктурный интерстициальный флюид со множественными микрокавернами. Плотный матрикс утолщает кортикальные пластинки, деформирует структуру кольцевидных остеонов и увеличивает шероховатость поверхности интерстициальных остеонов. Остеоны со сглаженной спайностью принимают вид гиперминерализованных мембран с облитерированными нанопорами. При этом микропоры костных пластинок расширяются, что в связи с блокадой матриксных нанопор направлено на компенсацию рисков ухудшения трансмембранного массообмена. Границы трабекул фестончаты за счет множественных микроэрозий, в зоне которых костных макрофагов не найдено. Многие эрозии имеют „тромбированный“ вид: заполнены сегрегированными частицами матриксного детрита. Таким же, но набухшим детритом, заполнены и внутренние каверны, многие из которых посредством микротрещин и соустий сообщаются между собой и с костномозговой поло- 


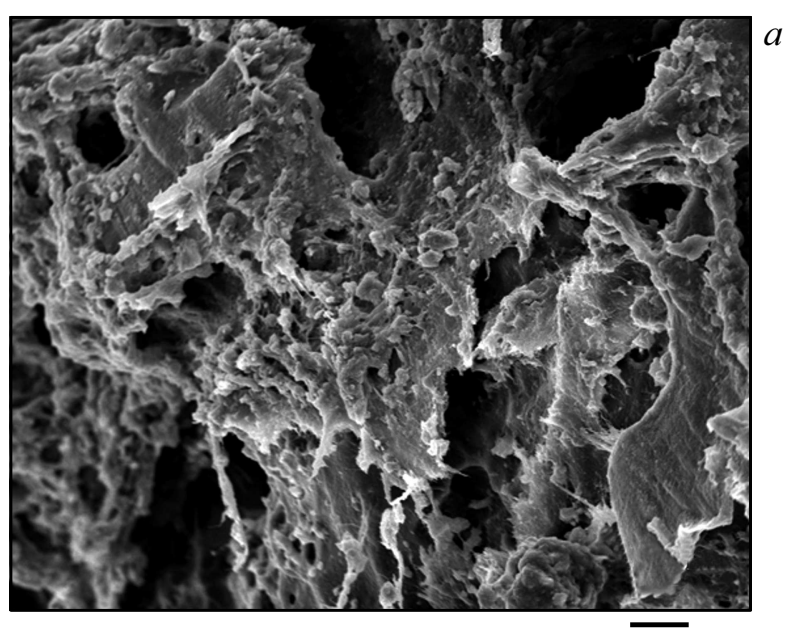

$20 \mu \mathrm{m}$

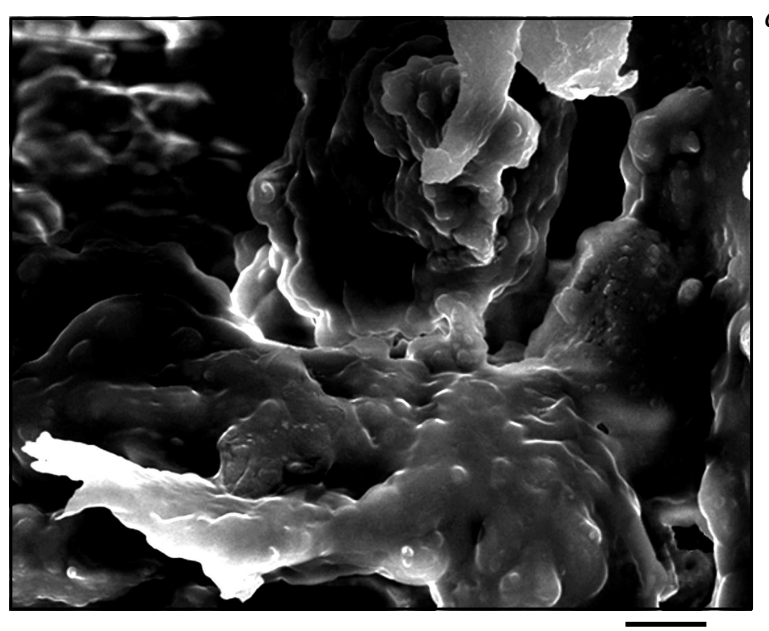

$10 \mu \mathrm{m}$



$20 \mu \mathrm{m}$



$10 \mu \mathrm{m}$

Рис. 5. СЭМ-изображения костного матрикса при туберкулезном остите без лечения $(a, b)$ и при туберкулезном остите после лечения $(c, d): a, c-1$ месяц, $b, d-2$ месяца.

стью. Вышеперечисленные деформационные структуры свидетельствуют о том, что в морфогенезе разрушения плотного костного матрикса основное значение имеют механохимические конфликты, обусловленные „щелочным“ разрушением „известкующегося“ ГА и сопровождающиеся хрупким распадом матрикса. Тренд подобных преобразований понятен - это адсорбция и уничтожение бактериальных частиц в „щелочном“ дебрисе секвестрируемых матриксных фрагментов.

По данным СЭМ (рис. 5, $c, d$ ) у животных 3-й группы на фоне специфического лечения туберкулезного остита наблюдается увеличение количества очагов остеобластического ремоделирования костной ткани, свидетельствующее об активных регенераторных процессах. Обращает на себя внимание то, что количество таких очагов на фоне лечения к 2 месяцам значительно увеличивается (рис. $5, d$ ). В очагах регенерации регистрируется гиперплазия матриксных пузырьков, накапливаются остеобласты с характерной отростчатой структурой и фор- мируются полиморфные костные пластинки. Процессы остеогенеза разбалансированы вследствие хаотичного разрастания костных пластинок и трабекул. Пластинки пересыщены кальцием, растут в свободный объем в виде пластинчато-игольчатых кальцийфосфатных фаз, предшественников ГА, таких как октакальцийфосфат, многие из них проникают в межтрабекулярное пространство и в просвет зарождающихся гаверсовых каналов.

\section{Заключение}

Таким образом, ключевыми эффектами воздействия микобактерий туберкулеза на структуру и физикохимические свойства костного матрикса являются:

1. Прогрессирующее и устойчивое к специфической терапии увеличение количества нестехиометрического ГА, сопровождающееся „защелачиваением“ межклеточного вещества, осаждением аморфизированных фосфа- 
тов кальция, охрупчением и мелкодисперсным распадом костного матрикса.

2. Преобладание роста кристаллов карбонат-ГА смешанного АБ-типа замещения приводит к разбалансированию процессов ремоделирования и чрезмерному остеогенезу, что сопровождается хаотичным разрастанием костных трабекул, минеральной облитерацией микропор и микрофитизацией костного матрикса.

3. Наличие в кристаллической решетке ГА участков „известкования“ усиливает „вяжущие“ свойства минеральной фазы костного матрикса и способствует химической иммобилизации и адгезии туберкулезных микобактерий на их поверхности.

Работа выполнена при поддержке программы ГПНИ „Химические технологии и материалы“ (задание 1.04).

\section{Список литературы}

[1] Марутко C.B. Электронный ресурс. Режим доступа: www.МедВестник.by. 2008. http://www.medvestnik.by/ru/ sovremennii_podxod/view/vnelegochnyj-tuberkulez-epidemiologicheskij-portret-6140-2008/

[2] Gaidash A.A., Sinitsa L.N., Babenko O.A., Lugovskoy A.A. // J. Osteoporosis. 2011. Vol. 2011. Article ID 162041. 7 p. DOI: $10.4061 / 2011 / 162041$

[3] Цубер В.К., Лесникович Л.А., Кулак А.И., Трофимова И.В., Петров П.Т., Трухачева Т.В., Коваленко Ю.Д., Красильникова В.Л. // Химико-фармацевтический журнал. 2006. T. 40. № 8. C. 48-51.

[4] Крутько В.К., Кулак А.И., Мусская О.Н. // Неорганические материалы. 2017. Т. 53. № 4. С. 427-434. DOI: $10.7868 / \mathrm{S} 0002337 \mathrm{X} 17040091$

[5] Мусскал О.Н., Кулак А.И., Крутько В.К., Лесникович Ю.А., Казбанов В.В., Житкова Н.С. // Неорганические материалы. 2018. Т. 54. № 2. С. 146-153. DOI: $10.7868 / \mathrm{S} 0002337 \mathrm{X} 18020033$

[6] Wilson R.M., Elliot J.C., Dowker S.E.P. // Am. Mineral. 1999. Vol. 84. P. 1406. ICSD POWD-12++[01-089-6438]

[7] Le Geros // Science. 1967. Vol. 155. P. 1409. [00-019-0272].

[8] Голованова О.А., Герк С.А., Куриганова А.Н., Измайлов Р.P. // Системы. Методы. Технологии. 2012. Т. 16. № 4. C. $131-139$.

[9] Смолеговский А.М. История кристаллохимии фосфатов. М.: Наука, 1986. 263 с.

[10] Власов Р.А., Меркулова Е.П., Мельник В.Ф., Крутько В.К., Кулак А.И., Мусская О.Н., Москалева Н.В. // Материалы межрегиональной научно-практической конференции оториноларингологов Сибири и Дальнего Востока с международным участием „Актуальные вопросы оториноларингологии“ // Под общей ред. д.м.н., проф. А.А. Блоцкого. Благовещенск, 2015. С. 70-74.

[11] Lafon J.P., Championa E., Bernache-Assollant D. // J. Europ. Ceram. Soc. 2008. Vol. 28. P. 139-147. DOI: 10.1016/j.jeurceramsoc.2007.06.009

[12] Комлев В.С., Фадеева И.В., Гурин А.Н., Ковалева Е.С., Смирнов В.В., Гурин Н.А., Баринов С.М. // Неорганические материалы. 2009. Т. 45. № 3. С. 373-378.

[13] Лемешева С.А., Голованова О.А., Туренков С.В. // Химия в интересах устойчивого развития. 2009. № 17. С. 327-332.

[14] Лемешева С.А., Голованова О.А., Муромцев И.В., Туренков С.В. // Вестник Омского ун-та. 2010. № 2. С. 106-112. 